\title{
Erratum to: Compatible ground-motion prediction equations for damping scaling factors and vertical-to-horizontal spectral amplitude ratios for the broader Europe region
}

\author{
S. Akkar - M. A. Sandıkkaya • B. Ö. Ay
}

Published online: 6 May 2014

C) Springer Science+Business Media Dordrecht 2014

\section{Erratum to: Bull Earthquake Eng (2014) 12:517-547 DOI 10.1007/s10518-013-9537-1}

There are some typos in the text that discusses the vertical spectrum trends given in Figs. 5 and 6. The vertical spectra shown in these figures are computed for median + sigma. To this end, the wording "median" in the last paragraph of page 530 and first paragraph of page 531 should be replaced with "median + sigma."

There is also another mistake in Fig. 8 and the corrected version is given in Fig. 1. This mistake does not affect our results or conclusions in the paper.

The online version of the original article can be found under doi:10.1007/s10518-013-9537-1.

S. Akkar $(\varangle)$

Department of Earthquake Engineering, Kandilli Observatory and Earthquake Research Institute, Boğaziçi University, Çengelköy, 34684 Istanbul, Turkey

e-mail: sinan.akkar@boun.edu.tr

\section{A. Sandikkaya}

Department of Civil Engineering, Earthquake Engineering Research Center,

Middle East Technical University, K6 Building, 06800 Ankara, Turkey

e-mail: askaya@metu.edu.tr

\section{A. Sandıkkaya}

Institut des Sciences de la Terre (ISTerre), Universite de Grenoble, 38041 Grenoble, France

B. Ö. Ay

European Centre for Training and Research in Earthquake Engineering, 27100 Pavia, Italy

e-mail: ozeray@gmail.com 

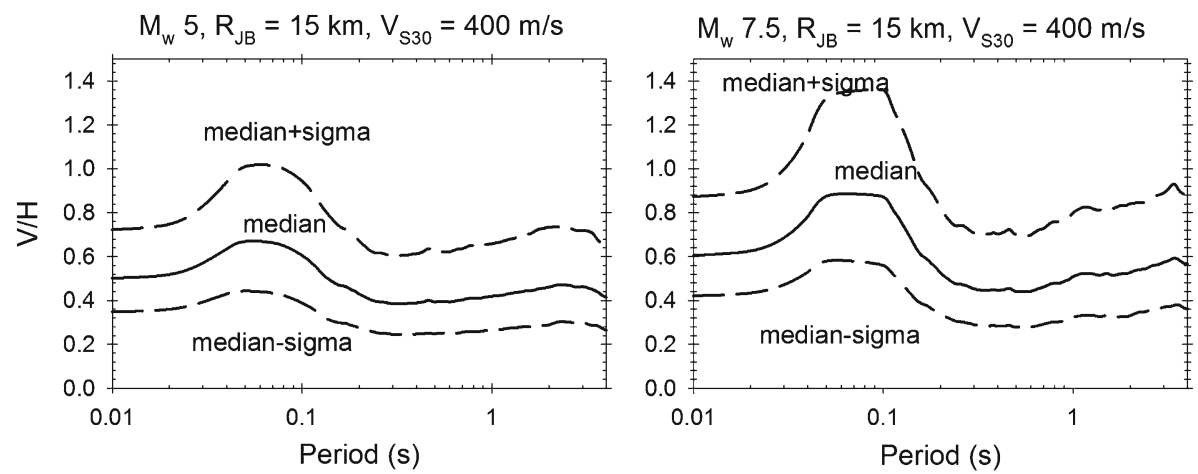

Fig. 1 Effect of aleatory variability in the proposed V/H GMPE

Acknowledgments Our thanks to Cyril Gomes (GEOTER International-Fugro Group) for alerting us to these errors. 